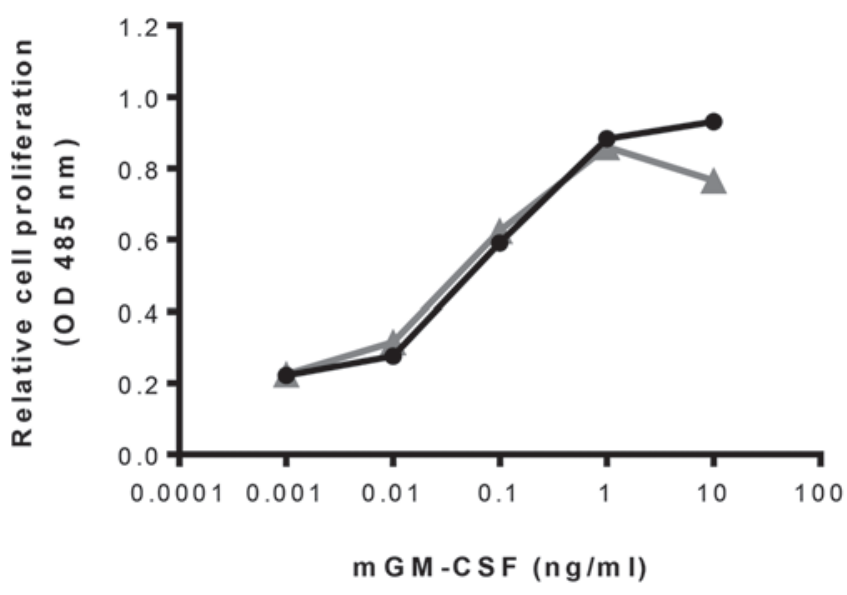

Abstract S120 Figure 1 Comparison of biological function of murine (m) GM-CSF produced after lentiviral-gene transfer and purchased purified protein (red: mGM-CSF produced through gene transfer, black: purchased mGM-CSF protein).

\section{S121 CELL TRACKING IN LUNG CANCER}

${ }^{1}$ SP Patrick*, ${ }^{2} \mathrm{~K}$ Kolluri*, ${ }^{2} \mathrm{AV}$ Davies, ${ }^{2}$ EK Sage, ${ }^{1} \mathrm{M}$ Lythgoe, ${ }^{2} \mathrm{~A}$ Edwards, ${ }^{1} \mathrm{TL}$ Kalber, ${ }^{2} \mathrm{SM}$ Janes. ${ }^{1}$ Centre for Advanced Biomedical Imaging, UCL, London, UK; ${ }^{2}$ Lungs for Living Research Centre, UCL, London, UK; *Joint first author

\subsection{6/thoraxjnl-2017-210983.127}

Introduction Lung cancer is the leading cause of cancer death worldwide with over $70 \%$ of patients presenting with incurable disease and few effective treatments. We previously demonstrated that mesenchymal stem cells transduced to express TNF-related apoptosis inducing ligand (TRAIL), will home to and induce apoptosis of tumour cells in vitro and reduce tumour growth in multiple in vivo models. A key unknown of cellular therapy is the location and duration of cells following intravenous delivery. ${ }^{111}$ Indium-oxine is established for lymphocyte tracking but it has low sensitivity and is toxic to cells. ${ }^{89}$ Zirconium-oxine is a novel PET tracer which has better sensitivity and lower toxicity. Our study aimed to label MSCTRAIL with ${ }^{89} \mathrm{Zr}$ with the aim of tracking cells in patients enrolled in the TACTICAL trial - an early phase trial delivering MSCTRAIL to patients with metastatic lung adenocarcinoma.

Methods MSC-TRAIL cells were incubated with multiple doses of ${ }^{89} \mathrm{Zr}$-oxine and label retention measured using a gamma counter. Cells were assessed for cell viability using cell proliferation assays, TRAIL expression was determined using flow cytometry and ELISA and apoptosis was determined using coculture experiments with luciferase expressing cancer cell lines and bioluminescent readout. DNA damage and cellular stress was assessed using western blotting. To determine whether radiolabelled cells could be detected in vivo, $2 \times 10^{5} 89 \mathrm{Zr}$ Oxine MSC-TRAIL cells were delivered intravenously and imaging was performed at multiple time points (Mediso PETCT, AMI-X).

Results ${ }^{89} \mathrm{Zr}$-oxine labelling at clinically relevant doses did not affect cell proliferation and therapeutic efficacy was maintained in co-culture experiments. There was no evidence of DNA damage and cell stress response and cellular phenotype was maintained. CT/PET imaging after labelling and delivery of the cells into mice showed good correlation with bioluminescent signal confirming its use a high sensitivity tracking tool.

Conclusion ${ }^{89} \mathrm{Zr}$-oxine can be used to successfully radiolabel genetically modified stem cells without effecting cell viability or therapeutic efficacy. We are currently performing in vivo studies to enable further translation into a clinical trial and will ultimately track MSC-TRAIL after patient administration via radiolabelling with ${ }^{89} \mathrm{Zr}$-oxine.

\section{S122 A ROLE FOR THE BONE MORPHOGENETIC PROTEIN TYPE 2 RECEPTOR (BMPR2) IN DIFFERENTIATION OF THE COMMON MYELOID PROGENITOR LINEAGE IN MICE AND HUMANS}

${ }^{1}$ A Crosby, ${ }^{1} \mathrm{C}$ Hadinnapola, ${ }^{1}$ UKPAH Cohort Study Consortium, 'E Groves, 'S Moore, ${ }^{1}$ BD Dunmore, ${ }^{2} \mathrm{M}$ Southwood, ${ }^{1} \mathrm{IP}$ Horan, ${ }^{1} \mathrm{M}$ Bleda, ${ }^{1} \mathrm{M}$ Haimel, ${ }^{1} \mathrm{~S}$ Gräf, 'MR Toshner, ${ }^{1} \mathrm{NW}$ Morrell. ${ }^{1}$ Cambridge University, Cambridge, UK; ${ }^{2}$ Papworth Hospital, Cambridge, UK

\subsection{6/thoraxjnl-2017-210983.128}

Rationale There is increasing evidence of a link between abnormalities in the myeloid cell lineage and pulmonary arterial hypertension (PAH). Heterozygous mutations in the gene encoding the bone morphogenetic protein type 2 receptor (BMPR2) are the most common genetic cause of PAH. We sought to characterise the impact of the genetic loss/reduction of $B M P R 2$ function in the myeloid lineage in mice and humans, and whether this altered susceptibility to PAH.

Methods Mx1-cre mice were crossed with bmpr $2^{\text {flox/flox }}$ mice. At approximately 8 weeks of age cre-recombinase was induced with polyinosinic-polycytidylic acid (Poly I:C). Control mice (bmpr $2^{\text {flox/flox }}$ mice with no cre) were also induced with Poly I:C. At approximately 16 weeks post-induction mice underwent right-heart catheterisation, exsanguination and tissue was removed for analysis. The spleens were weighed and histology was performed on the femurs. Mouse data are presented as mean \pm SEM. In a large cohort of PAH patients with $(n=160)$ and without $(\mathrm{n}=831)$ BMPR2 mutations blood count indices were analysed. Data presented as median [IQR].

Results 16 weeks after induction of cre-recombinase in Mx1cre/bmpr $2^{\text {flox/flox }}$ mice we observed significant increases $(\mathrm{p}<0.05)$ in red blood cells $\left(\times 10^{6} / \mathrm{mm}^{3}\right) \quad(12.7 \pm 0.9$ compared with 12.1 \pm 0.2$)$, haematocrit (\%) (64.8 \pm 0.7 compared with $62.6 \pm 1)$ and haemoglobin $(\mathrm{g} / \mathrm{dl})(16 \pm 0.9$ compared with 15.4 \pm 0.2 ) compared with bmpr $2^{\text {flox/flox }}$ mice alone. A significant increase in circulating monocytes $\left(\times 10^{3} / \mathrm{mm}^{3}\right)$ was also observed $(\mathrm{p}<0.05) \quad(0.4 \pm 0.05$ compared with $0.3 \pm 0.05)$. In addition, we identified a significant increase $(\mathrm{p}<0.05)$ in megakaryocytes in the femurs $(80 \pm 10$ compared with $17 \pm 5)$ and a significant increase $(\mathrm{p}<0.01)$ in the ratio of spleen weight/ body weight $(0.003 \pm 0.0001$ compared with $0.002 \pm 0.0001)$ in Mx1-cre/bmpr $2^{\text {flox/flox }}$ mice. During right heart catheterisation right ventricular systolic pressures were similar in both groups. In PAH patients significant differences $(\mathrm{p}<0.05)$ were seen in haemoglobin (BMPR2 mutation: $162 \mathrm{~g} / \mathrm{L}$ [151.75-173]) vs. no mutation: $150 \mathrm{~g} / \mathrm{L}$ [135 - 163]), haematocrit (0.48 [0.45-0.52] vs. $0.44[0.41-0.48])$ and white blood cells $(8.8[7.3-10.4]$ vs. 8.11 [6.77-9.61]).

Conclusions we have identified a role for bmpr2 in the differentiation of the mouse myeloid lineage, which was also confirmed in $\mathrm{PAH}$ patients with BMPR2 mutations. BMPR2 appears particularly important in the differentiation of megakaryocyte-erythrocyte lineage. 


\section{Respiratory epidemiology}

\section{S123 EXACERBATION RISK AND CHARACTERISATION OF THE UK'S ASTHMA POPULATION, FROM INFANCY TO OLD AGE}

${ }^{1} \mathrm{Cl}$ Bloom, ${ }^{2} \mathrm{~F}$ Nissen, ${ }^{2}$ Douglas, ${ }^{2} \mathrm{~L}$ Smeeth, ${ }^{1} \mathrm{P}$ Cullinan, ${ }^{1} \mathrm{JK}$ Quint. ${ }^{1} / \mathrm{mperial}$ College London, London, UK; ' London School of Hygiene and Tropical Medicine, London, UK

10.1136/thoraxjnl-2017-210983.129

Introduction and Objectives Few studies have examined the characteristics of a general asthma population; most have focussed on more severe patients or severe exacerbations. We sought to provide the first description of the UK's general asthma population.

Methods Population-based cohort study, April 2007 to September 2015, using linked primary and secondary care electronic healthcare records (Clinical Practice Research Datalink, Hospital Episode Statistics). Four age cohorts: 'Under $5 \mathrm{~s}$ ', '5 to 17 s', '18 to 54 s', '55+', are described. Exacerbation risk factors, including asthma severity (measured by the 2016 BTS stepwise approach), were assessed using random effects Poisson regression.

Results 424326 patients with current asthma were eligible ( $\mathrm{N}$, median follow-up: 'Under $5 \mathrm{~s}$ ' $=17,320,1$ year; ' 5 to $17 \mathrm{~s}$ ' $=82,707,3.3$ years; ' 18 to $54 \mathrm{~s}$ ' $=210,724,4$ years; '55 $+^{\prime}=113,575,5.1$ years). Over $60 \%$ of the total study population had mild asthma (BTS steps 1/2). There were differences between the cohort's characteristics, including by gender, disease severity and exacerbation pattern. The oldest cohort had the highest proportion, and the ' $5-17$ s' the lowest, on BTS step 3 or higher (figure 1). In the ' $55+$ ' cohort, $23 \%$ also had a diagnosis of COPD. Of the patients who exacerbated, the youngest cohort had the highest proportion of patients that exacerbated more than once a year ('Under $5 \mathrm{~s}$ ' $=54.7 \%$, ' 5 to $17 \mathrm{~s}$ ' $=13.1 \%$, ' 18 to $54 \mathrm{~s}$ ' $=18.8 \%$, ' $55+$ ' $=34.1 \%)$. The rate of any exacerbations was highest in the oldest cohort and lowest in the ' 5 to $17 \mathrm{~s}$ ' cohort (rate per 10 person-years, (95\% CI), 'Under $5 \mathrm{~s}$ ' $=4.27(4.18-4.38)$, '5 to $17 \mathrm{~s}$ ' $=1.48$ $(1.47-1.50), \quad$ ' 18 to $54 \mathrm{~s}^{\prime}=3.22 \quad(3.21-3.24), \quad$ ' $55+$ ' $=9.40$ (9.37-9.42)). In all cohorts, exacerbation rates increased with increasing asthma severity, after adjusting for potential confounders including gender, socioeconomic status, smoking, BMI, atopy, rhinitis, gastroesophageal reflux, anxiety, depression and COPD.

Conclusions This is the first descriptive study of the UK's general asthma population. The majority of UK asthma patients had mild disease, and did not exacerbate during follow-up. Patients aged $\geq 55$ years had the lowest proportion with mild asthma and the highest rate of exacerbations; the opposite was found in patients aged between 5 to 17 years. Increasing BTS step was significantly associated with increasing exacerbation rates across all generations.

\section{S124 TRENDS IN MORTALITY FROM IDIOPATHIC PULMONARY FIBROSIS IN THE EUROPEAN UNION: AN OBSERVATIONAL STUDY OF THE WHO MORTALITY DATABASE FROM 2001 - 2013}

${ }^{1} \mathrm{DC}$ Marshall, ${ }^{2} \mathrm{DD}$ Salciccioli, ${ }^{3} \mathrm{BS}$ Shea, ${ }^{4} \mathrm{P}$ Akuthota. 'University of Oxford, Oxford, UK; ${ }^{2}$ Mount Auburn Hospital, Cambridge, US; ${ }^{3}$ Alpert Medical School of Brown University, Providence, US; ${ }^{4}$ University of California San Diego, La Jolla, US

\subsection{6/thoraxjnl-2017-210983.130}

Background Idiopathic pulmonary fibrosis (IPF) is the most common of the idiopathic interstitial pneumonias and is characterised by progressive accumulation of scar tissue in the lungs. It carries a poor prognosis, with a median survival of only approximately 3 years after diagnosis. No previous reports have attempted to describe trends in IPF mortality across the European Union (EU).

Methods Country-level data for IPF mortality, identified in the WHO mortality database using ICD-10 codes for the period 2001-2013. Joinpoint analysis was performed to describe trends throughout the observation period.

Findings Median mortality was 3.75/1 00000 (IQR, 1.375.30) and 1.50/1 00000 (IQR, 0.65-2.02) for males and females, respectively. IPF mortality increased in the majority of the EU countries with the exceptions of Denmark, Croatia, Austria and Romania. There was a significant disparity in rates across Europe ranging from 0.41-12.1/100 000 for men and 0.24-5.63/100 000 for women. Most notable increases were

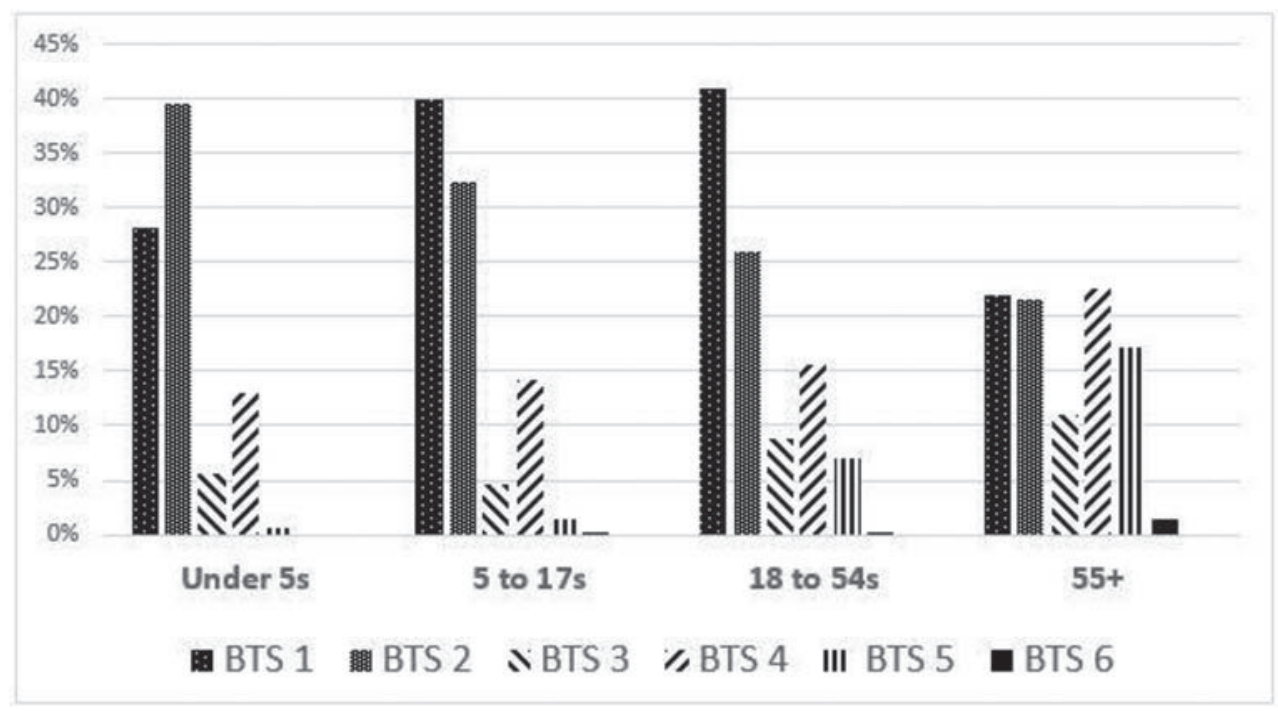

Abstact S123 Figure 1 Proportion of asthma patients in each BTS step by age cohort. 